\title{
Shallow Foundation Settlement Quantification: Application of Hybridized Adaptive Neuro-Fuzzy Inference System Model
}

\author{
Mariamme Mohammed, ${ }^{1}$ Ahmad Sharafati, ${ }^{2}$ Nadhir Al-Ansari $\left(\mathbb{D},{ }^{3}\right.$ \\ and Zaher Mundher Yaseen $\mathbb{D}^{4}$ \\ ${ }^{1}$ College of Agricultural Engineering Sciences, University of Baghdad, Baghdad, Iraq \\ ${ }^{2}$ Department of Civil Engineering, Science and Research Branch, Islamic Azad University, Tehran, Iran \\ ${ }^{3}$ Civil, Environmental and Natural Resources Engineering, Luleå University of Technology, 97187 Luleå, Sweden \\ ${ }^{4}$ Faculty of Civil Engineering, Ton Duc Thang University, Ho Chi Minh City, Vietnam \\ Correspondence should be addressed to Zaher Mundher Yaseen; yaseen@tdtu.edu.vn
}

Received 12 September 2019; Revised 12 December 2019; Accepted 18 January 2020; Published 22 February 2020

Academic Editor: Castorina S. Vieira

Copyright (C) 2020 Mariamme Mohammed et al. This is an open access article distributed under the Creative Commons Attribution License, which permits unrestricted use, distribution, and reproduction in any medium, provided the original work is properly cited.

\begin{abstract}
Settlement simulating in cohesion materials is a crucial issue due to complexity of cohesion soil texture. This research emphasis on the implementation of newly developed machine learning models called hybridized Adaptive Neuro-Fuzzy Inference System (ANFIS) with Particle Swarm Optimization (PSO) algorithm, Ant Colony optimizer (ACO), Differential Evolution (DE), and Genetic Algorithm (GA) as efficient approaches to predict settlement of shallow foundation over cohesion soil properties. The width of footing $(B)$, pressure of footing $\left(q_{a}\right)$, geometry of footing $(L / B)$, count of SPT blow $(N)$, and ratio of footing embedment $(D f / B)$ are considered as predictive variables. Nonhomogeneity and inconsistency of employed dataset is a major concern during prediction modeling. Hence, two different modeling scenarios (i) preprocessed dataset (PP) and (ii) nonprocessed (initial) dataset (NP) were inspected. To assess the accuracy of the applied hybrid models and standalone one, multiple statistical metrics were computed and analyzed over the training and testing phases. Results indicated ANFIS-PSO model exhibited an accurate and reliable prediction data intelligent and had the highest predictability performance against all employed models. In addition, results demonstrated that data preprocessing is highly essential to be performed prior to building the predictive models. Overall, ANFISPSO model showed a robust machine learning for settlement prediction.
\end{abstract}

\section{Introduction}

1.1. Research Background. In practice, three types of shallow foundation settlements are commonly encountered, and these are immediate settlement, consolidation settlement, and secondary compression settlement [1]. Immediate settlement is encountered when the load is applied immediately after initiating a structure. It is primarily a consequence of soil-grain distortion and reorientation. Consolidation settlement, on the other hand, is time-dependent and generally takes longer time to occur. It occurs due to water pressure dissipation over time. Secondary compression settlement results as a soil creep; it is a viscous flow under load with no changes in effective stress. The total settlement of a foundation is the sum of the above three components. For cohesionless soils, the only source of concern is immediate settlement, while consolidation and secondary compression settlements are the primary factors associated with cohesive soils.

Generally, sand deposits are more heterogeneous than clay deposits; hence, there is likely to be higher differential settlements in sand deposits compared to clay deposits [2]. Due to the high level of permeability of cohesionless soils, it takes a shorter time for the settlement to occur after applying load [3]. The result of such a quick settlement is a relative rapid superstructure deformation and the consequential inability to curtail the damage and prevent further deformation. Furthermore, structural failures can result from 
excessive settlement [4]. The design of shallow foundations is mainly controlled by two major criteria which are the settlement of the foundations and the bearing capacity of the footing. However, settlement often controls the design process rather than the bearing capacity; this is mainly the case when the width of footing is more than 1 meter (3-4ft) [5]. Therefore, settlement prediction is an essential and important criterion during the design of shallow foundations.

On cohesionless soils, the prediction of the settlement of shallow foundations is complicated and yet to be understood because settlement is governed by many uncertain and unquantifiable factors [6]. Some of these uncertain factors include the distribution of the applied stress [7], the soils' stress and strain properties, the compressibility of the soil, and the difficulty in obtaining undisturbed samples of cohesionless soils for laboratory testing [8].

1.2. Literature Review and Research Motivation. There are several methods in the geotechnical literature (theoretical and experimental) for the prediction of the settlement of shallow foundations on several types of soil $[2,9-14]$. As presented in Figure 1, usually several variables are incorporated with the magnitude of soil settlement such as net applied pressure $\left(q_{o}\right)$, Poisson's ratio of soil $\left(\mu_{s}\right)$, average modulus of elasticity of soil $\left(E_{s}\right)$, and foundation dimensions ( $B$ and $L$ ). Thus, the settlement behavior is a highly complex geotechnical engineering problem owing to the association with varying variability.

Due to the difficulty in obtaining undisturbed samples for cohesionless soils, many methods for settlement prediction have concentrated on the correlations between in situ investigations, such as the standard penetration test (SPT) [15], cone penetration test (CPT) [16], dilatometer test [17], plate load test [18], and screw plate load test. In most of the available methods, the problem is simplified by introducing several assumptions related to the factors that affect settlement. As a result, these available methods (ranging from purely empirical to complex nonlinear finite elements) cannot achieve a consistent and accurate settlement prediction [19]. Over the literature, several comparative studies using machine learning models demonstrated inconsistent of settlement prediction magnitudes. Hence, reliable alternative model is always the inspiration of geotechnical scientists to explore and investigate [20]. Machine learning models exhibited a new era of modeling methodologies for various engineering applications [21-27]. Within the settlement determination, artificial neural network (ANN) models have been introduced to this field since about three decades ago [28-32]. This was followed by several implementations over the past two decades using diverse AI models including gene expression programming [33, 34], support vector machine [35], least square support vector machine [36], and neuro-fuzzy network [37, 38]. Among several AI models reported in the literature, adaptive neural fuzzy inference system (ANFIS) model exhibited a distinguished modeling technique in the field of geotechnical engineering [39]. This is owing to its robustness in capturing the high complex nonlinearity and nonstationarity of the

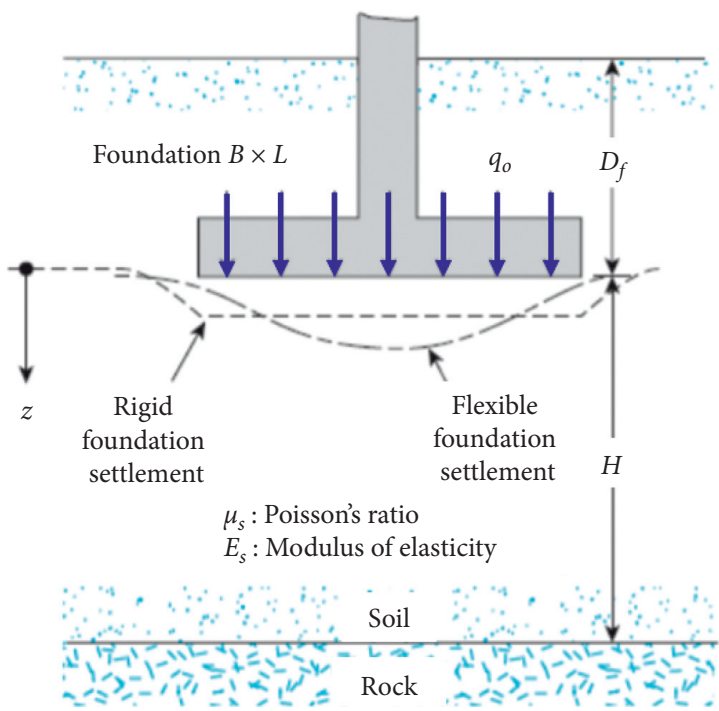

FIGURE 1: Some of the related variables on foundation-soil settlement.

experimental laboratory dataset. However, the main drawback associated with standalone AI models is the internal hyperparameter tuning, and thus, the integration of these models with bioinspired optimization algorithms and produce what so-called hybrid model is the era of modeling strategy for simulating complex engineering problems [40-42]. In the current research, the feasibility of four different nature-inspired algorithms (i.e., PSO, ACO, DE, and GA) are investigated to tune ANFIS model as a predictive paradigm for simulating shallow foundation settlement. The selection of those optimizers is owing to their capacity in tuning the internal parameters of AI models and that was evidenced through several established research studies over the literature $[43,44]$.

1.3. Research Objectives. To the best knowledge of the current research, the development of a hybridized dataintelligence model based on the integration of bioinspired optimization algorithms with ANFIS model was proposed with the aim of achieving more reliable and robust settlement prediction results. The explored hybrid model was verified for viability on the shallow foundation settlement within cohesion soil properties. The major benefit of the proposed models is the ability to simulate the nonlinearity connection between the inputs (correlated attributes) and the output (target variable) without the need for a predefined formulation. Additionally, the concept is more like the introduced settlement prediction methodologies but with the added advantage of the intelligence to capture the complex mechanism of settlement variability.

\section{Applied Hybrid Models}

Soft computing models are mainly used to explain complex engineering problems which are highly stochastic and nonlinear. This is the case when the traditional models are not able to be adequately applied. SC is the basic form of 


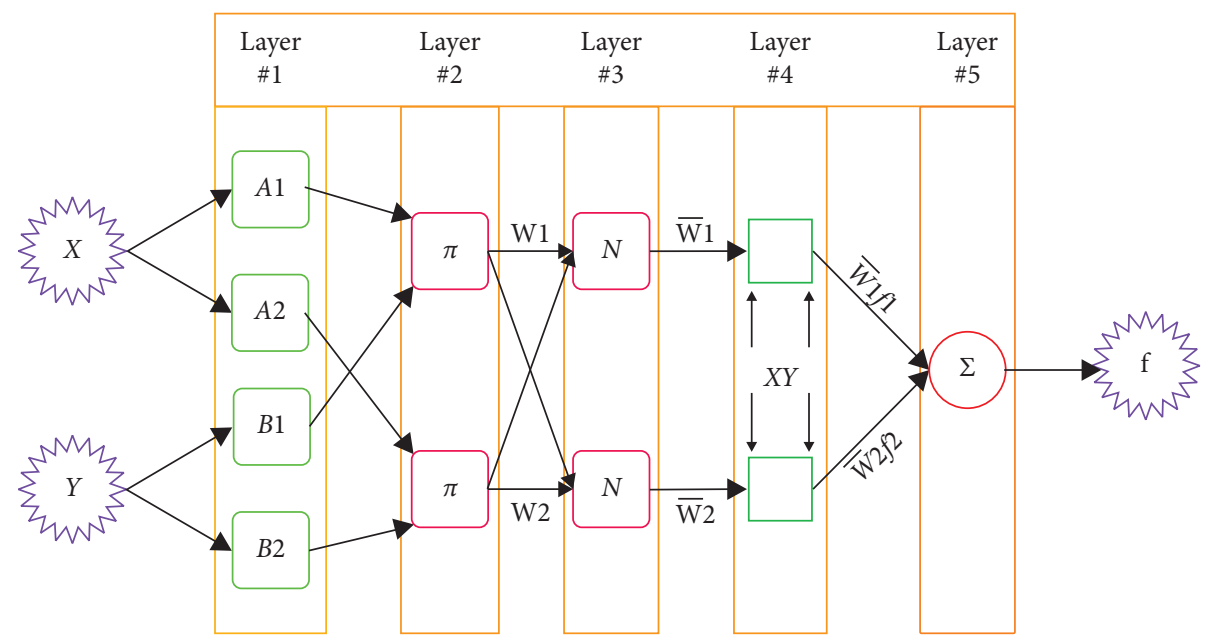

FIgURE 2: The conceptual mapping of adaptive neuro-fuzzy inference system model.

artificial intelligence that can be implemented to solve difficult applications using the aspect on intelligent human brain behavior. Also, the soft computing modeling is following the basic concept of black box that is required no preknowledge of the investigated problem. Furthermore, both partial truth and approximation can be considered in soft computing.

2.1. Adaptive Neuro-Fuzzy Inference System (ANFIS). The fuzzy logic (FL) concept was conceived several years back as a data processing method which allows partial set membership [45]. The FL method of data analysis was mainly popular because people do not intend the precise numerical input. Its major advantages include the provision of an easy way to arrive at a conclusion based on noisy or imprecise input data [46, 47]. A proper knowledge of the shape and type of fuzzy rules, as well as the membership functions, is important in order to achieve the best results. However, some cases require the use of the time-consuming methods such as trial and error. The model can be trained using artificial neural networks. A hybrid combination of neural networks with fuzzy systems could produce a more robust model with numerous advantages [48, 49].

Therefore, a neuro-fuzzy system could be considered as a hybrid algorithm which can make decisions based on fuzzy and, at the same time, a modern soft computing-based method in terms of ANN. Jang introduced ANFIS in 1993 while Sugeno fuzzy system was developed based on the learning capability of ANN [50]. In a fuzzy system, the basic and most important components are the rules. The required rules will be optimized using ANN [51, 52].

The first proposed ANFIS model had five layers. The schematic structure of ANFIS is presented in Figure 2(b). The utilized rules are as follows:

Rule \# 1: If $X$ is $A_{1}$ and $Y$ is $B_{1}$, then $f_{1}=p_{1} x+q_{1} y+r_{1}$, Rule \#2: If $X$ is $A_{2}$ and $Y$ is $B_{2}$, then $f_{2}=p_{2} x+q_{2} y+r_{2}$, where $A_{1}-A_{2}$ and $B_{1}-B_{2}$ are membership functions for input $x$ and input $y$, respectively.

In layer 1 , each node is a square node creating the membership grades. Utilizing the membership function, inputs $(x$ and $y$ ) would be translated into linguistic terms:

$$
\mathrm{O}_{1, i}=\mu_{A_{i}}(x), \quad i=1,2 \text {, }
$$

where $x$ is the input value to node $i$ and $A_{i}$ is the linguistic term. Furthermore, $O_{i}^{1}$ is the membership function of $A_{i}$. Available types for membership functions are Gaussian, triangular, and trapezoidal. The Gaussian function has the following formula:

$$
\mu_{A_{i}}(x)=\exp \left(-\left(\frac{x-a_{i}}{b_{i}}\right)^{2}\right)
$$

where $a_{i}$ and $b_{i}$ are the antecedent parameters.

Similarly, in the second layer, each node is a circle one, and the output would be obtained using the following function:

$$
O_{2, i}=w_{i}=\mu_{A_{i}}(x) * \mu_{B_{i}}(x), \quad i=1,2,
$$

where $w_{i}$ is the weight influence of the rule. In the third layer, the nodes calculate the ratio of the rules weight divided by the sum of all weights as follows:

$$
\mathrm{O}_{3, i}=\overline{w_{i}}=\frac{w_{i}}{w_{1}+w_{2}}, \quad i=1,2 \text {. }
$$

All nodes in the fourth layer are square having the function as follows:

$$
O_{4, i}=\overline{w_{i}} f_{i}=\overline{w_{i}}\left(p_{i} x+q_{i} y+r_{i}\right), \quad i=1,2,
$$

where $\overline{\mathrm{w}_{\mathrm{i}}}$ is the output of the third layer. $\mathrm{p}_{\mathrm{i}}, \mathrm{q}_{\mathrm{i}}$, and $\mathrm{r}_{\mathrm{i}}$ are the consequent parameters.

Finally, the fifth layer consists of only one circle node $\left(\sum\right)$ as follows:

$$
O_{5, i}=\sum_{i} \bar{w}_{i} f_{i}=\frac{\sum_{i} w_{i} f_{i}}{\sum_{i} w_{i}}, i=1,2 .
$$




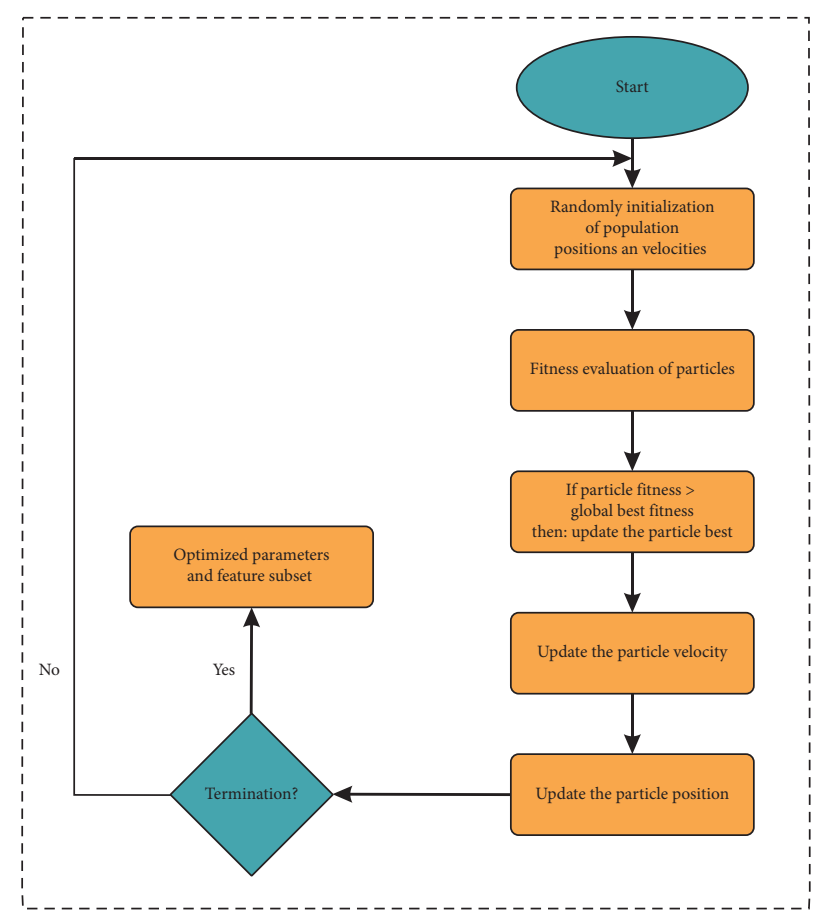

(a)

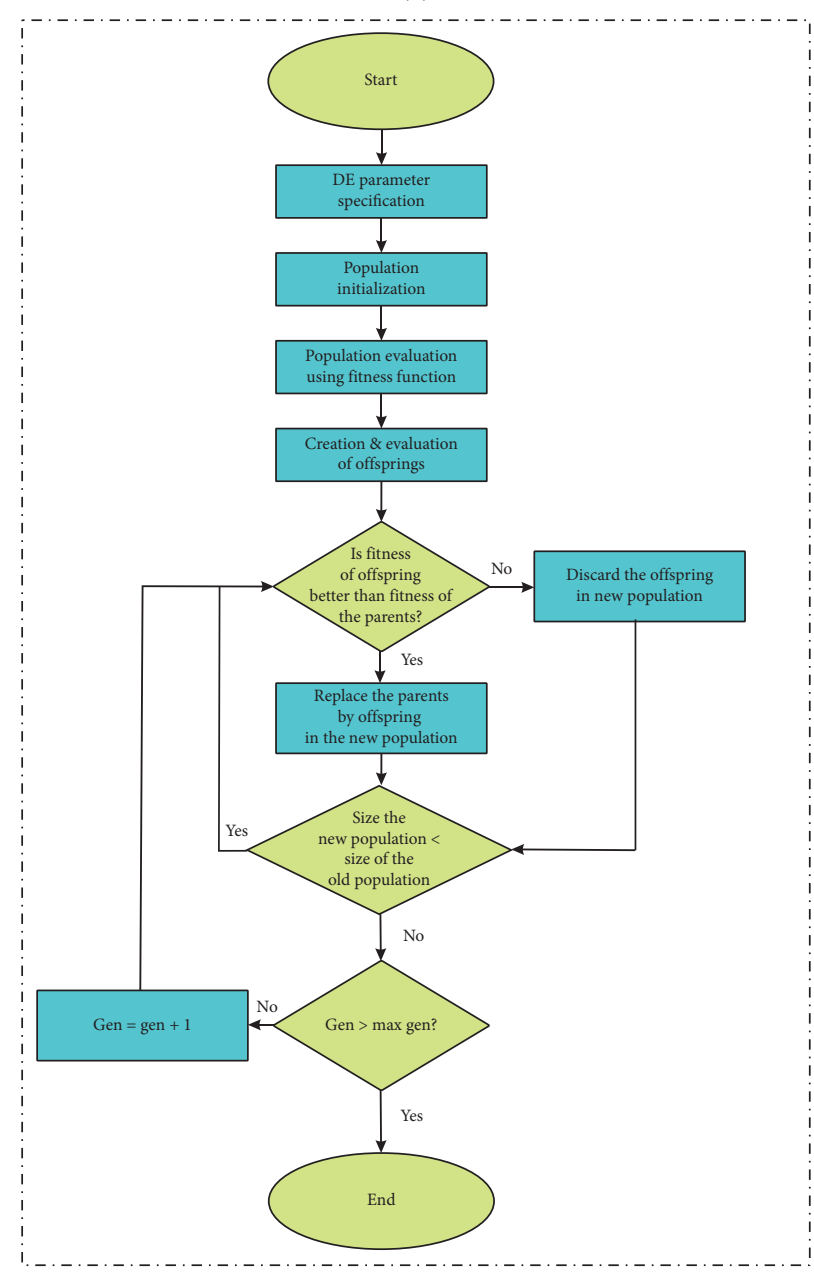

(c)

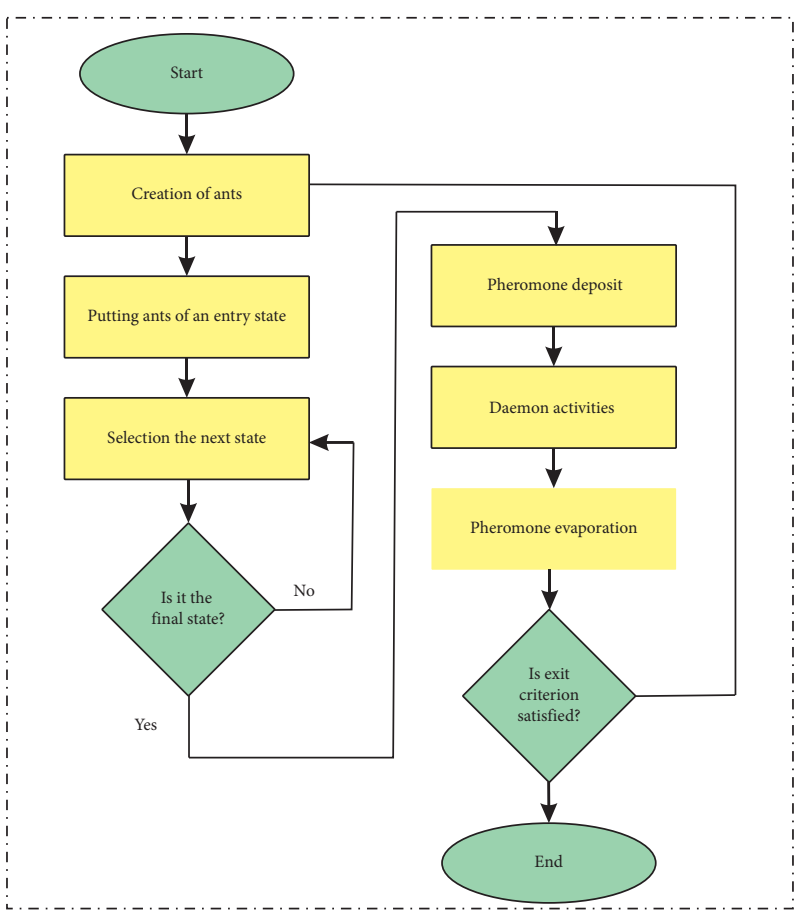

(b)

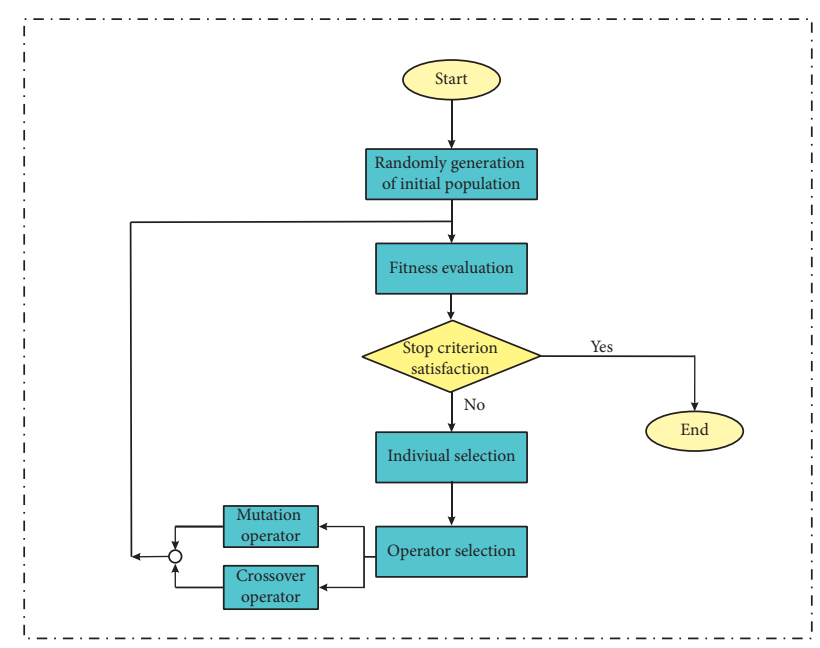

(d)

FIgURE 3: (a) Functional flowchart of PSO algorithm, (b) functional flowchart of ACO algorithm, (c) typical flowchart of DE algorithm, and (d) flowchart of genetic algorithm. 


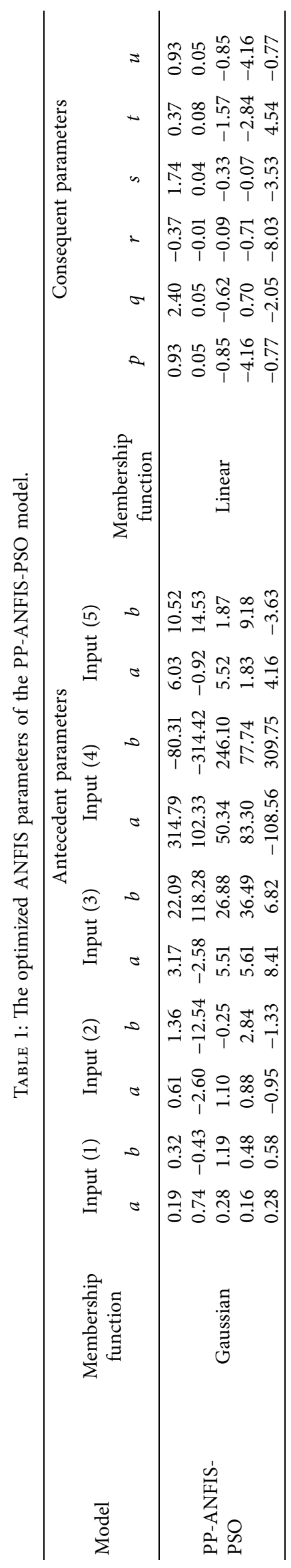


The schematic view of ANFIS modeling is presented in Figure 2.

Herein, five membership functions (Gaussian function) are considered for each input variable and five membership functions (liner function) for output. Totally, the proposed ANFIS model has 80 parameters (50 antecedent parameters and 30 consequent parameters) which were optimized by proposed nature-inspired optimization algorithms.

2.2. Particle Swarm Optimization (PSO) Algorithm. PSO algorithm was developed as an optimization method based on the behavior and movements of a community of birds, fish, and insects. It was introduced by Reynolds when he considered 3 kinds of operators designated as alignment, separation, and cohesion. The algorithm was modelled in the likeness of a group of particles flowing within a search space in a bid to achieve an optimal point. The particles within the search space adjust their movement based on their own experience and on the experience of the other particles [52-54]. Similarly, they also adjust their speed based on their own experience and on the experience of the other particles. They change their position with respect to the position/ velocity/distance of the best particle. The particle update rule is as follows:

$$
p=p+v
$$

with,

$$
v=v+c_{1} \text { rand. }\left(p_{\text {best }}-p\right)+c_{2} \text { rand. }\left(g_{\text {best }}-p\right),
$$

where $p, v, c_{1}, c_{1}, p_{\text {best }}, g_{\text {best }}$, and rand are the position, direction, the weight of local data, the weight of global data, best position of the particles, best position of the swarm, and a random value, respectively. The following equations are used to update the particles' velocities:

$$
V_{i}^{t+1}=v_{i}^{t}+c_{1} U_{1}^{t}\left(p b_{i}^{t}-p_{i}^{t}\right)+c_{2} U_{2}^{t}\left(g b_{i}^{t}-p_{i}^{t}\right),
$$

In the above equation, the three major terms are inertia, personal influence, and social influence, respectively. Figure 3(a) presents the flowchart of PSO.

\subsection{Ant Colony Optimization (ACO) Algorithm. Dorigo} introduced ant colony system some years back, but in recent years, many researchers have focused on the extended versions of the ant system [55]. Being that the ACO can solve static and dynamic problems, they are applicable in several optimization problems. Activities such as foraging (food searching), cooperative transport, labor division, and brood sorting are governed by what is commonly known as stigmergy which enables them to achieve self-organization. Although there are simple individuals in the ant colonies, it could be considered as one of the most complicated but wellorganized natural structures.

The pheromone produced by the ants is trailed by the other ants in order to find the shortest path to a food source. This algorithm uses a similar procedure to arrive at the optimum point in the search space. The ants can only make forward or backward movements; hence, a stepwise decision process will be applied by the ants to find the best solution to a given problem [56-58]. Figure 3(b) presents the working flowchart of ACO.

2.4. Differential Evolution (DE) Algorithm. Some of the objective functions in real engineering problems are discrete, nonlinear, or multidimensional while some may have local minima. Such cases require a population-based algorithm with stochastic features to obtain the solution. This quality is obtainable in the Differential Evolution (DE) algorithm introduced by Storn and Price in 1996 [59, 60]. To optimize a function with $n$ real parameters, the vectors would appear as follows:

$$
x_{i}, G=\left[x_{i}, i, G, x_{2}, G, \ldots, x_{n}, i, G\right], \quad i=1,2, \ldots, k,
$$

where $G$ is the generation number. A definition of the upper and lower boundaries for each parameter would give

$$
x L j \leq x j, i, 1 \leq x U j .
$$

The initial values for the parameters would be randomly selected with identical probability. The flowchart of the DE algorithm is presented in Figure 3(c).

2.5. Genetic Algorithm (GA). GA was developed as an evolutionary search algorithm based on the Darwinian principle of natural selection for solving optimization problems [61]. The algorithm initiates with a random generation of the initial population before proceeding to the evaluation of the fitness of the individuals using the fitness function. The next stage is the selection stage using methods such as Roulette Wheel. The two operators mainly used by the algorithm to generate new offspring are crossover and mutation [62, 63]. Figure 3(d) presents the schematic presentation of the GA.

The optimized ANFIS parameters (antecedent and consequent parameters) through the PSO algorithm (superior model) are presented in Table 1 .

2.6. Prediction Performance Metrics. In this research, the mean performance (MP) index was computed to evaluate the proposed hybrid data-intelligence models. The main merit of this index is the incorporation all of the performance metrics including root mean square error (RMSE), mean absolute error (MAE), Legate and McCabe's index (LMI), correlation coefficient (CC), Willmott's index (WI), and relative root mean square error (RRMSE) [41, 64-67]. The MP metric can be expressed mathematically as follows [68]:

$$
\mathrm{MP}=\frac{(\widehat{\mathrm{RMSE}}+\widehat{\mathrm{MAE}}+\widehat{\mathrm{LMI}}+\widehat{\mathrm{CC}}+\widehat{\mathrm{WI}}+\mathrm{R} \widehat{\mathrm{RMSE}})}{7}
$$

where $\widehat{\mathrm{RMSE}}, \widehat{\mathrm{MAE}}, \widehat{\mathrm{LMI}}, \widehat{\mathrm{CC}}, \widehat{\mathrm{WI}}$, and $\widehat{\mathrm{RMS}} \widehat{\mathrm{RM}}$ are the standardized values of the employed performance indices of $i^{\text {th }}$ model (hybridized ANFIS models) and can be computed as follows: 
TABLE 2: The statistics of the employed parameters in training and testing phases.

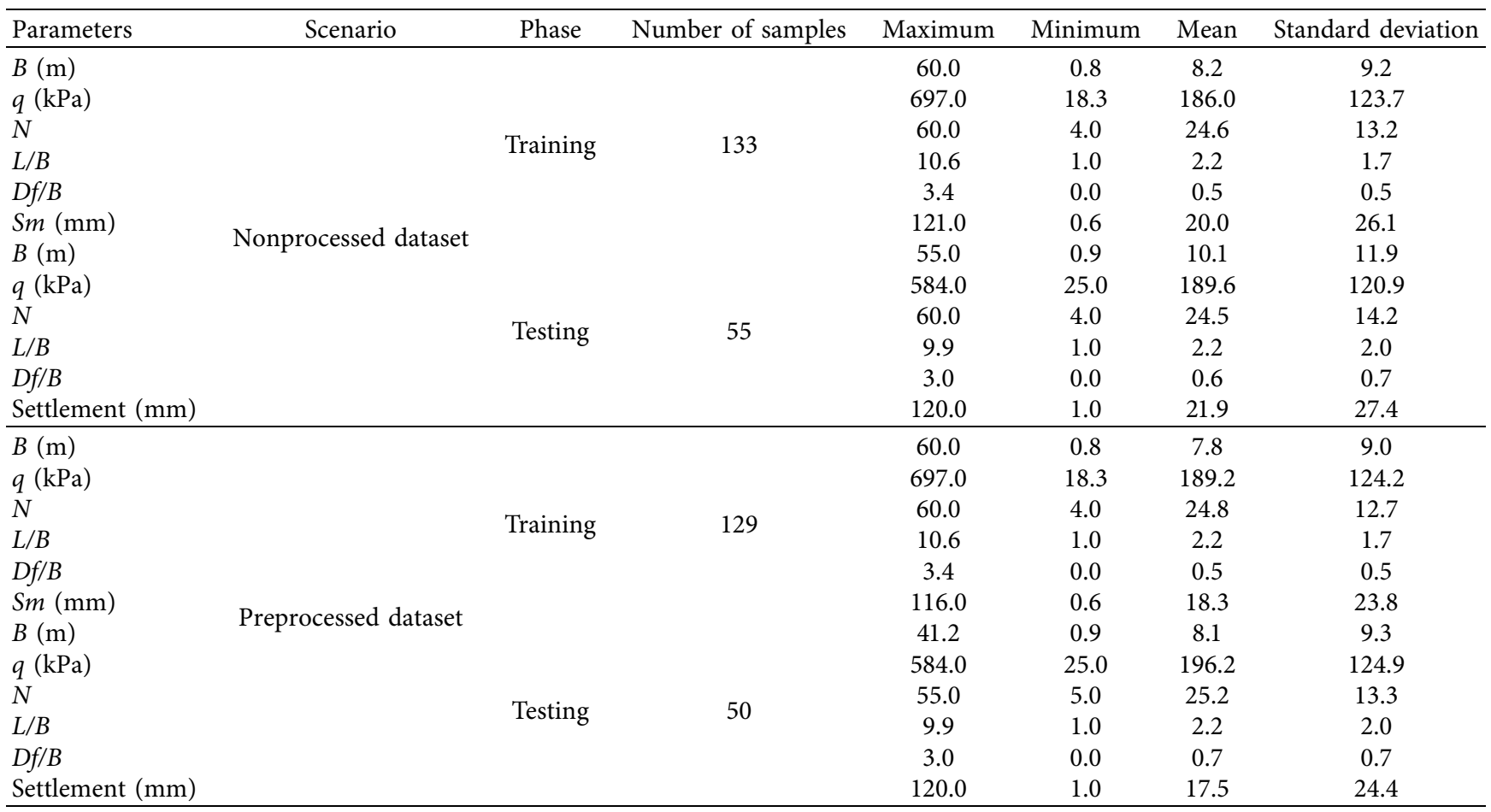

TABLE 3: The computed performance metrics over the training and testing phases and using preprocessed dataset scenario.

\begin{tabular}{|c|c|c|c|c|c|c|}
\hline Models & RMSE (mm) & MAE (mm) & LMI & $\mathrm{CC}$ & WI & SRMSE \\
\hline \multicolumn{7}{|l|}{ Training phase } \\
\hline PP-ANFIS & 7.88 & 5.04 & 0.66 & 0.94 & 0.97 & 43.05 \\
\hline PP-ANFIS-PSO & 6.10 & 3.50 & 0.76 & 0.97 & 0.98 & 33.35 \\
\hline PP-ANFIS-DE & 16.94 & 11.45 & 0.22 & 0.71 & 0.79 & 92.54 \\
\hline PP-ANFIS-ACO & 17.24 & 11.95 & 0.19 & 0.69 & 0.79 & 94.22 \\
\hline PP-ANFIS-GA & 8.17 & 5.96 & 0.60 & 0.94 & 0.97 & 44.64 \\
\hline \multicolumn{7}{|l|}{ Testing phase } \\
\hline PP-ANFIS & 13.47 & 8.87 & 0.38 & 0.85 & 0.92 & 76.87 \\
\hline PP-ANFIS-PSO & 9.02 & 6.50 & 0.54 & 0.93 & 0.96 & 51.47 \\
\hline PP-ANFIS-DE & 20.21 & 14.07 & 0.01 & 0.57 & 0.71 & 115.39 \\
\hline PP-ANFIS-ACO & 20.84 & 14.74 & -0.03 & 0.55 & 0.70 & 118.96 \\
\hline PP-ANFIS-GA & 11.59 & 8.34 & 0.42 & 0.88 & 0.94 & 66.17 \\
\hline
\end{tabular}

TABLE 4: The computed performance metrics over the training and testing phases and using nonprocessed dataset scenario.

\begin{tabular}{|c|c|c|c|c|c|c|}
\hline Models & RMSE $(\mathrm{mm})$ & $\operatorname{MAE}(\mathrm{mm})$ & LMI & $\mathrm{CC}$ & WI & SRMSE \\
\hline \multicolumn{7}{|l|}{ Training phase } \\
\hline NP-ANFIS & 8.38 & 5.84 & 0.65 & 0.95 & 0.97 & 41.99 \\
\hline NP-ANFIS-PSO & 8.09 & 4.92 & 0.71 & 0.95 & 0.97 & 40.49 \\
\hline NP-ANFIS-DE & 17.54 & 12.12 & 0.28 & 0.74 & 0.82 & 87.83 \\
\hline NP-ANFIS-ACO & 18.26 & 13.05 & 0.23 & 0.71 & 0.81 & 91.44 \\
\hline NP-ANFIS-GA & 12.18 & 7.47 & 0.56 & 0.89 & 0.93 & 60.97 \\
\hline \multicolumn{7}{|l|}{ Testing phase } \\
\hline NP-ANFIS & 16.30 & 10.82 & 0.41 & 0.86 & 0.92 & 74.57 \\
\hline NP-ANFIS-PSO & 14.10 & 9.88 & 0.46 & 0.86 & 0.93 & 64.49 \\
\hline NP-ANFIS-DE & 20.73 & 14.83 & 0.19 & 0.66 & 0.79 & 94.87 \\
\hline NP-ANFIS-ACO & 21.54 & 15.95 & 0.13 & 0.64 & 0.77 & 98.56 \\
\hline NP-ANFIS-GA & 16.58 & 12.17 & 0.34 & 0.80 & 0.89 & 75.85 \\
\hline
\end{tabular}



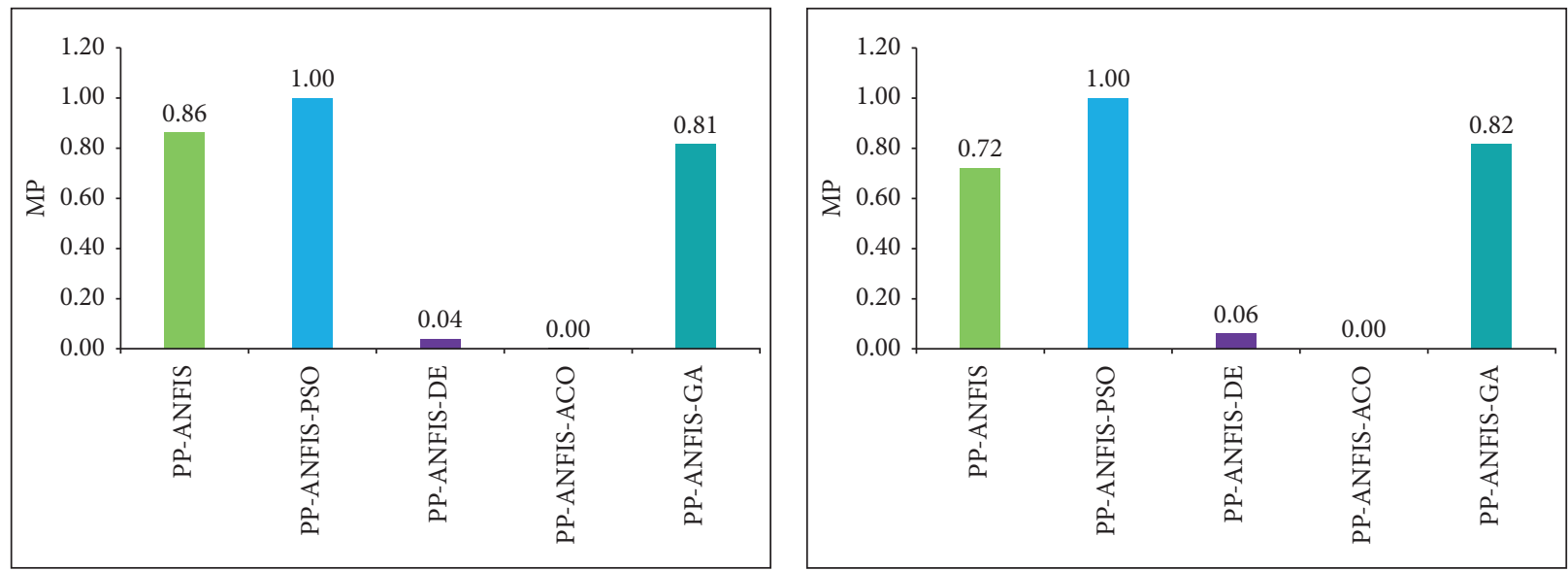

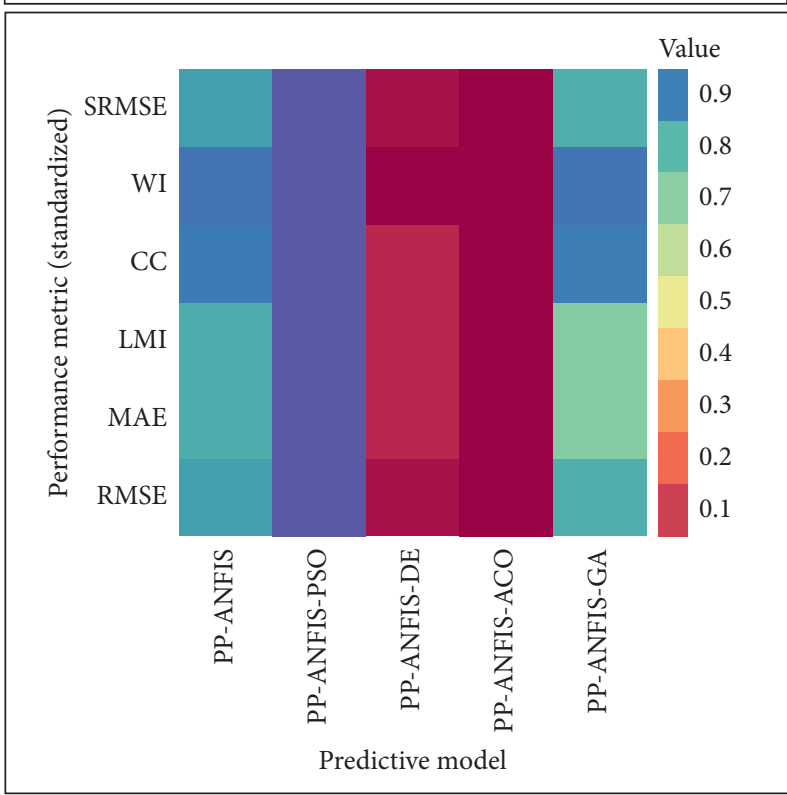

(a)

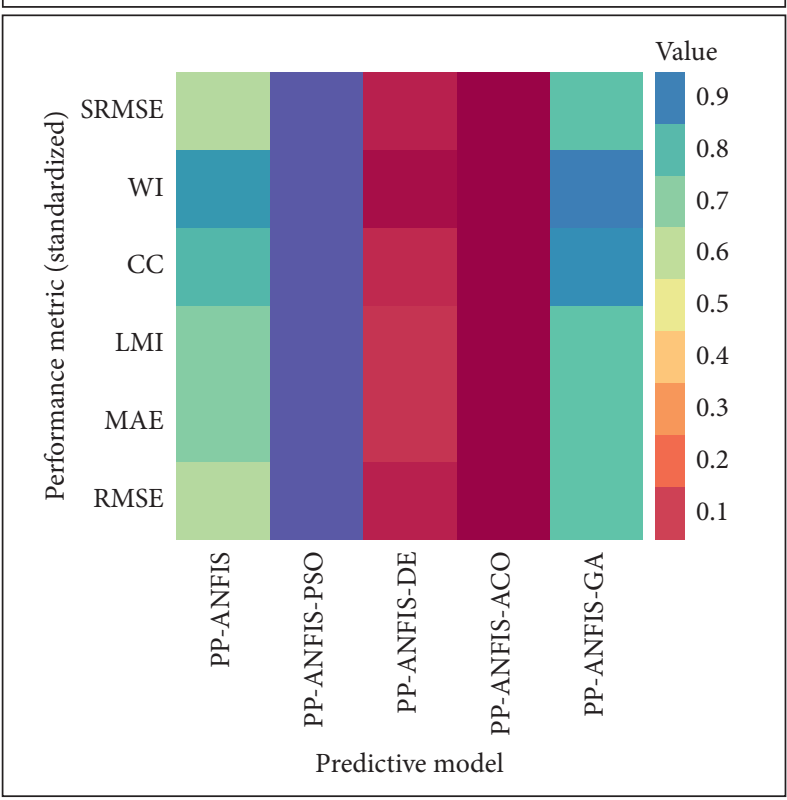

(b)

FIGURE 4: The mean performance index and heat graph presentations for the applied hybrid ANFIS models using the preprocessed data (PP) scenario: (a) training phase and (b) testing phase.

$$
\begin{aligned}
\widehat{\mathrm{RMSE}} & =\frac{\left(\mathrm{RMSE}_{\max }^{\square}-\mathrm{RMSE}_{\text {Model }(i)}^{\square}\right)}{\left(\mathrm{RMSE}_{\max }^{\square}-\mathrm{RMSE}_{\min }^{\square}\right)} \\
\widehat{\mathrm{MAE}} & =\frac{\left(\mathrm{MAE}_{\max }^{\square}-\mathrm{MAE}_{\text {Model }(i)}^{\square}\right)}{\left(\mathrm{MAE}_{\max }^{\square}-\mathrm{MAE}_{\min }^{\square}\right)}, \\
\widehat{\mathrm{LMI}} & =\frac{\left(\mathrm{LMI}_{\text {Model }(i)}^{\square}-\mathrm{LMI}_{\min }^{\square}\right)}{\left(\mathrm{LMI}_{\max }^{\square}-\mathrm{LMI}_{\min }^{\square}\right)}, \\
\widehat{\mathrm{CC}} & =\frac{\left(\mathrm{CC}_{\text {Model }(i)}^{\square}-\mathrm{CC}_{\min }^{\square}\right)}{\left(\mathrm{CC}_{\max }^{\square}-\mathrm{CC}_{\min }^{\square}\right)}, \\
\widehat{\mathrm{WI}} & =\frac{\left(\mathrm{CC}_{\text {Model }(i)}^{\square}-\mathrm{CC}_{\min }^{\square}\right)}{\left(\mathrm{CC}_{\max }^{\square}-\mathrm{CC}_{\min }^{\square}\right)}, \\
\widehat{\mathrm{PMSE}} & =\frac{\left(\mathrm{PRMSE}_{\max }^{\square}-\mathrm{PRMSE}_{\text {Model }(i)}^{\square}\right)}{\left(\mathrm{PRMSE}_{\max }^{\square}-\mathrm{PRMSE}_{\min }^{\square}\right)} .
\end{aligned}
$$

\section{Data Description and Input Model Development}

The proposed hybrid and standalone ANFIS models were constructed for the training and testing phases using field measurements of settlement of shallow foundation. The obtained data are corresponding to the foundation dimensions and soil properties with 188 observations [69]. Based on the geotechnical engineering prospect, the settlement is associated with several variabilities such as footing width $(B)$, soil compressibility within the effective influencing depth, and the net footing pressure $\left(q_{a}\right)$. Other variables such as footing embedment ratio $(D f / B)$, footing geometry length to width ration $(L / B)$, and count of SPT blow $(N)$ are the related variables considered to build the input attribute matrix of the settlement prediction. The details of employed datasets over training and testing phases are presented in Table 2. The dataset represents a wide range 


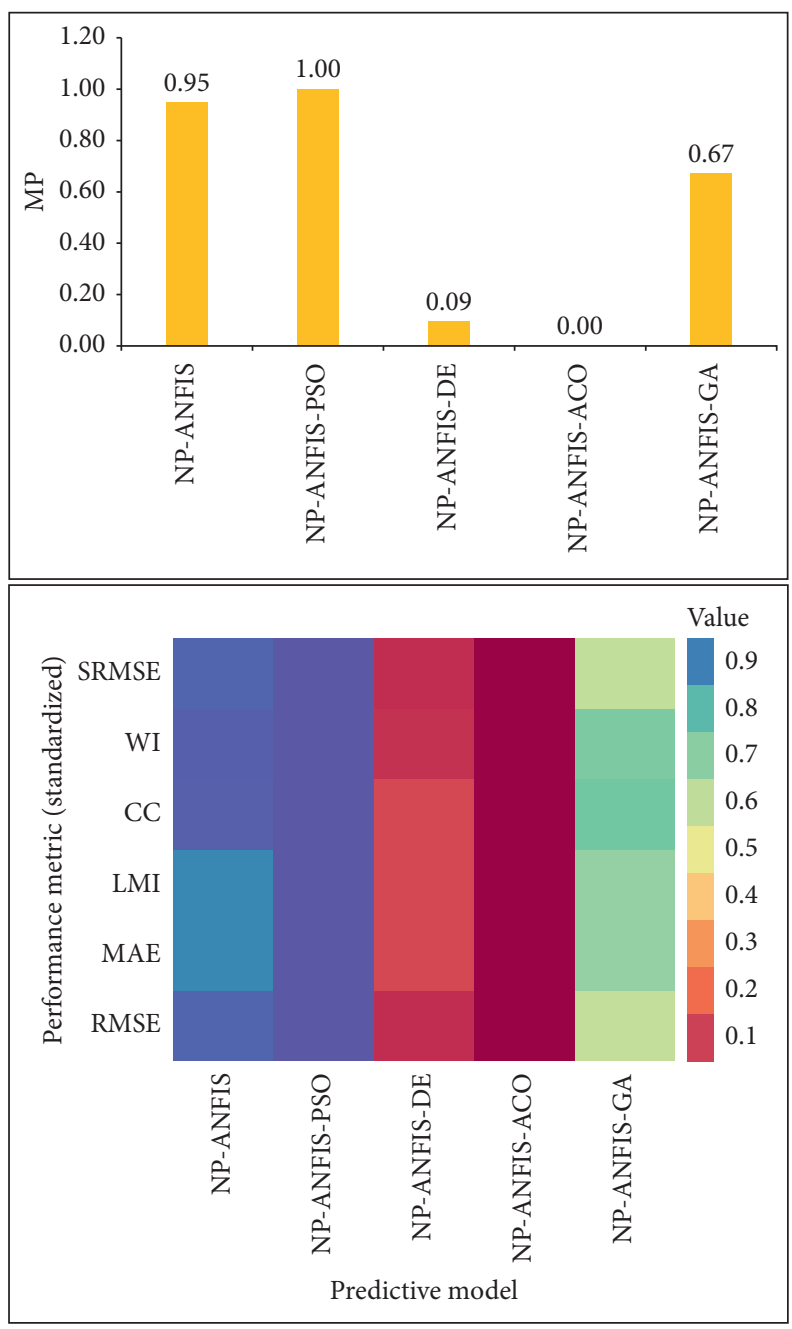

(a)

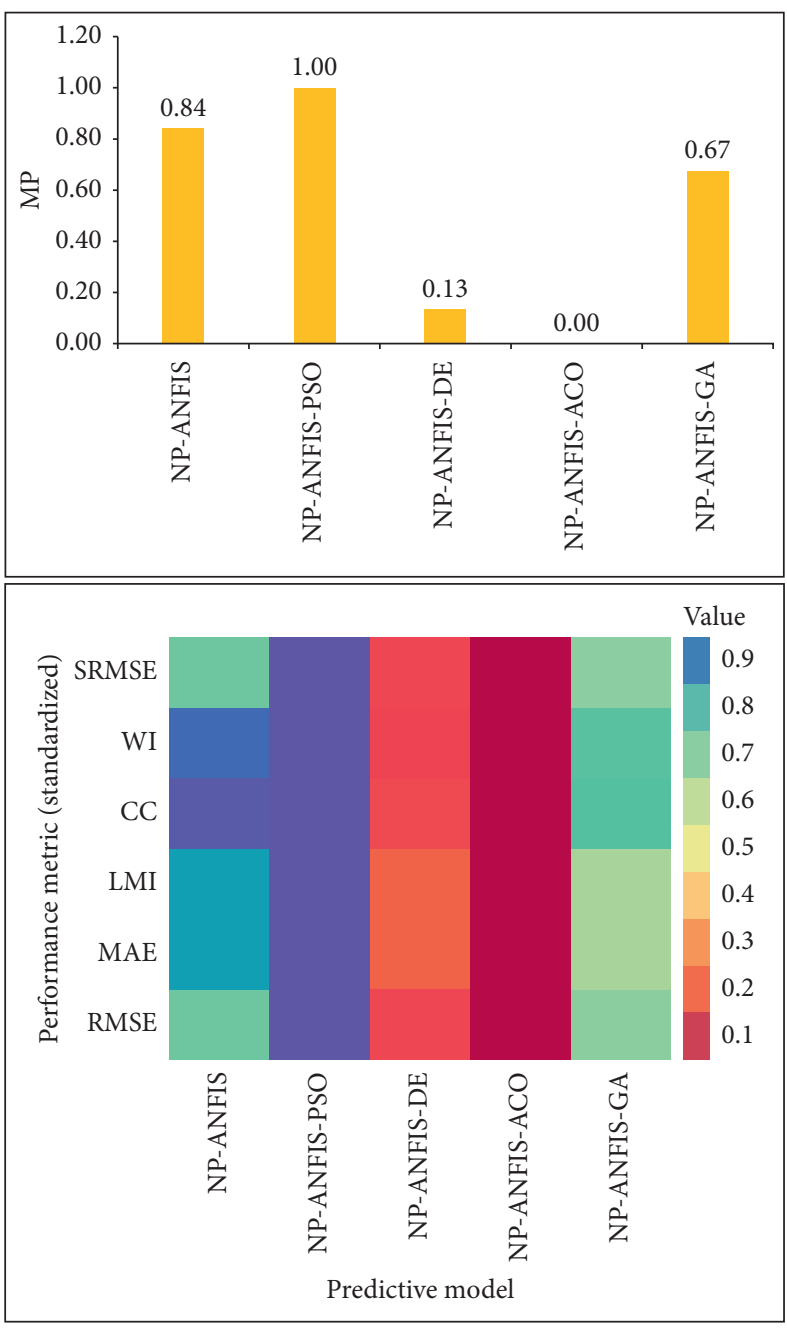

(b)

FIGURE 5: The mean performance index and heat graph presentations for the applied hybrid ANFIS models using the nonprocessed data (NP) scenario: (a) training phase and (b) testing phase.

of variation. The nonprocessed dataset was divided into 133-55 observations for the training-testing phases, whereas the preprocessed dataset was divided into 129-50 observations for the training-testing phases. The optimal data division was attained based on trial and error procedure in accordance with the obtained predictability performance.

\section{Application, Analysis, and Discussion}

The main motivation of the current research is to investigate the viability of the different versions of hybrid ANFIS models for predicting shallow foundation settlement. The limitations of the empirical formulation to simulate the exact relationship between the soil settlement and those various foundation loading and soil properties emphasize the implementation of data-intelligence models where more robust and reliable predictive models can be explored to configure the internal mechanism between the dependent and independent variables. Indeed, proposing such a reliable data-intelligence predictive model can contribute to the possibility of reliable foundation design in addition to various geotechnical engineering perspectives. The developed hybrid ANFIS models are appraised in different comparisons in accordance with statistical metrics, diagnostic plots, and error distributions between the laboratory measures and computed settlement values over the training and testing phases.

Using numerical validation, Tables 3 and 4 report the performance metrics (RMSE, MSE, LMI, CC, WI, and SRMSE) for the classical ANFIS, ANFIS-PSO, ANFIS-ACO, ANFIS-DE, and ANFIS-GA and for the two investigated scenarios (i.e., PP and NP). Generally, the execution of the developed models over the training phase showed a superior predictability in comparison with the testing phase and for both scenarios. In both scenarios and over the training phase, the hybrid ANFIS-PSO model exhibited the best results of settlement prediction with minimum absolute error measures $(\mathrm{RMSE}=6.1 \mathrm{~mm}$ and $\mathrm{MAE}=3.5 \mathrm{~mm})$ for the preprocessed dataset and $(\mathrm{RMSE}=8.09 \mathrm{~mm}$ and $\mathrm{MAE}=4.92 \mathrm{~mm}$ ) for the nonprocessed dataset. This can be best explained due to the 


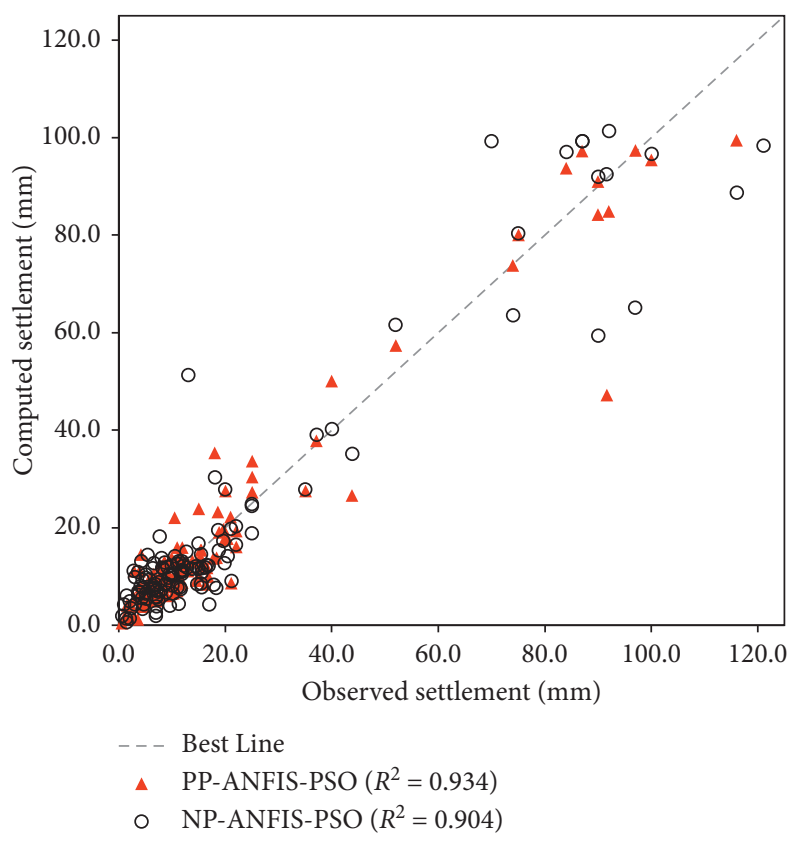

(a)

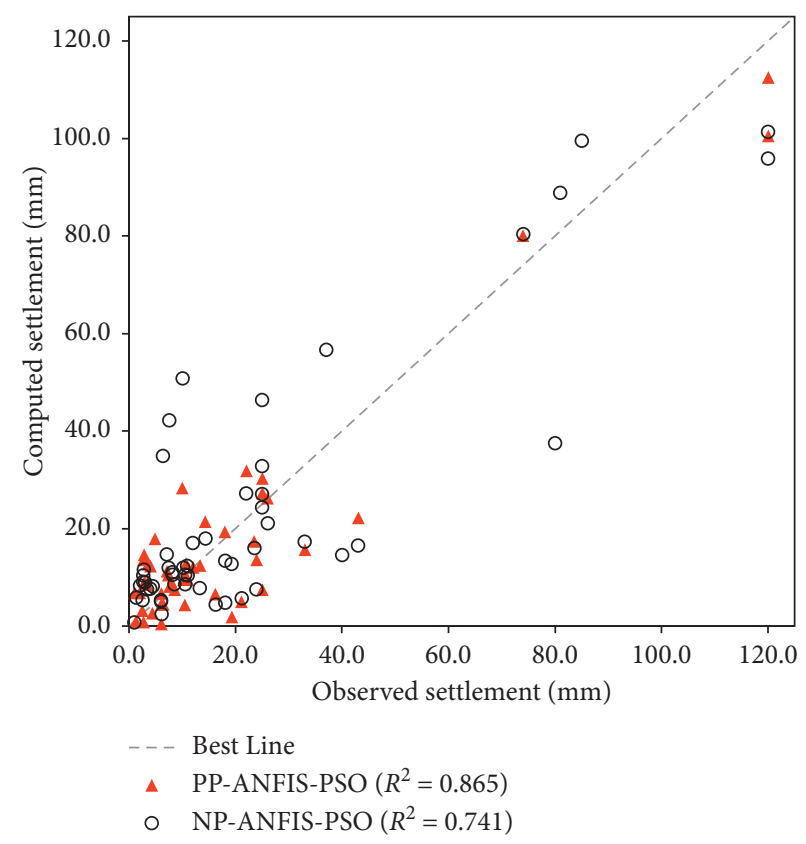

(b)

Figure 6: The scatter plot presentation between the observed settlement measurement and predicted values using the accurate hybrid intelligence (i.e., ANFIS-PSO) (both modeling scenarios): (a) training phase and (b) testing phase.

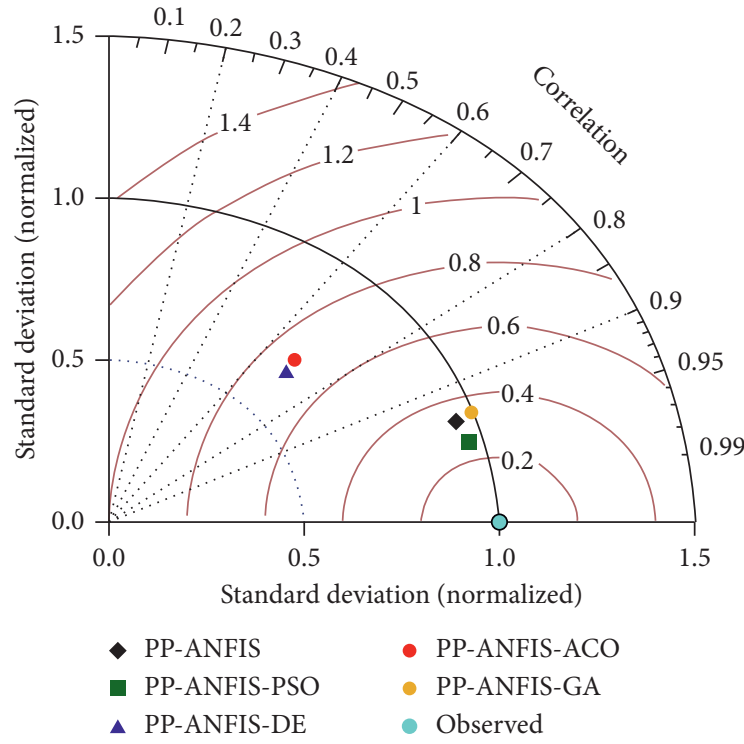

(a)

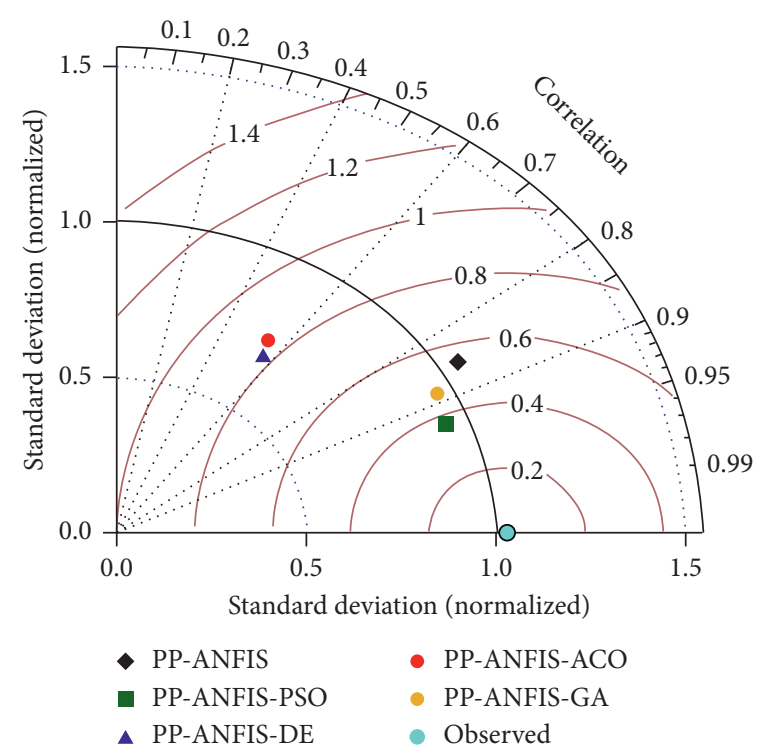

(b)

FIGURE 7: Normalized Taylor diagrams of predicted and observed shallow foundation settlement for the preprocessed dataset scenario: (a) training phase and (b) testing phase.

potential of the particle swarm optimizer in tuning the membership function parameters of the ANFIS predictive model. This is in synchronization with various other applied engineering problems [70-72]. On the other aspect, the data preprocessing demonstrated an excellent procedure where to produce more meaningful information for the predictive model. In other words, data preprocessing provided in more detectable manner information for the learning process of the established intelligence predictive models. Over the testing phase, ANFIS-PSO model displayed the best prediction results of settlement with minimum absolute error measures $(\mathrm{RMSE}=9.02 \mathrm{~mm}$ and $\mathrm{MAE}=6.5 \mathrm{~mm})$ for the preprocessed dataset and $(\mathrm{RMSE}=14.1 \mathrm{~mm}$ and $\mathrm{MAE}=9.88 \mathrm{~mm})$ for the nonprocessed dataset.

Figures 4 and 5display the mean performance (MP) index of all computed prediction measures metrics in addition to the 


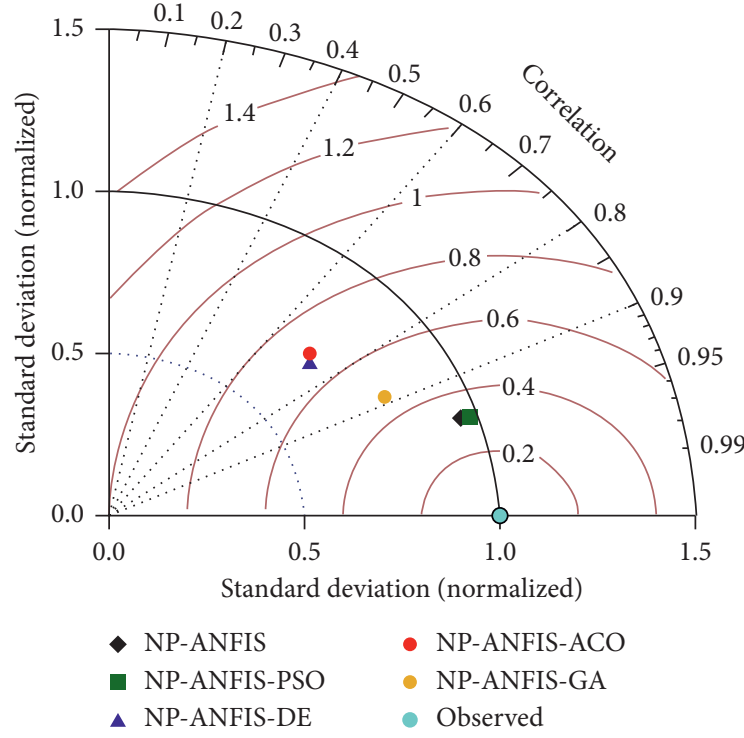

(a)

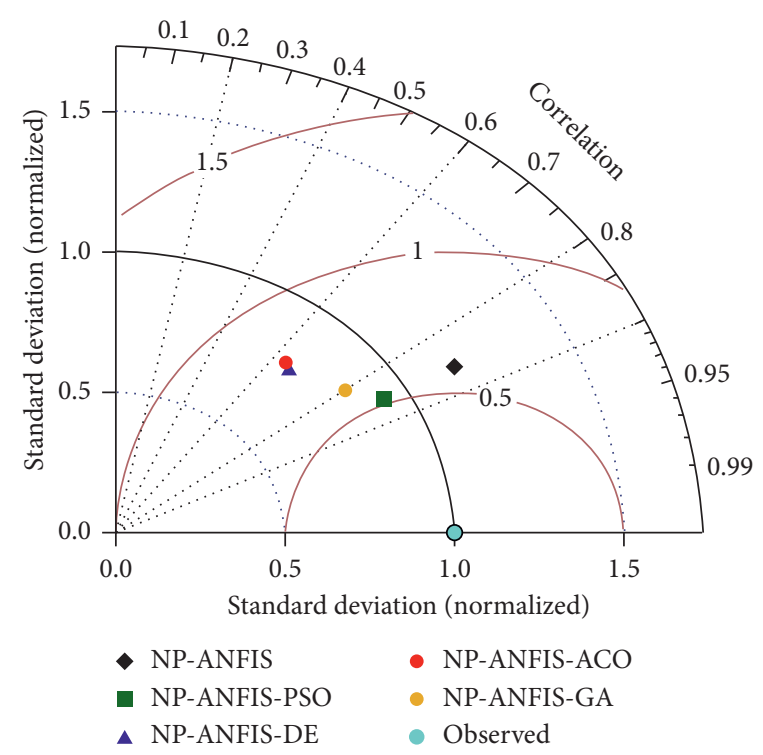

(b)

FIGURE 8: Normalized Taylor diagrams of predicted and observed shallow foundation settlement for the nonprocessed scenario: (a) training phase and (b) testing phase.

heat map for both inspected modeling scenarios PP and NP, respectively. Figures 4(a) and 5(a) present the models training phase while Figures 4(b) and 5(b) report the testing phase. In harmony with revealed numerical metrics of Tables 3 and 4, the hybrid ANFIS-PSO models showed the accurate prediction for the shallow foundation settlement with superior MP index value.

The performance of the applied hybrid models was examined using scatter plot graphs. The scatter plot is an excellent graphical evaluation method to depict the variance between the measured settlement and the computer model's computation (see Figure 6). Based on the variance around the fit line and the magnitude of the correlation coefficient, the best predictive model can be determined. Figure 6 exhibits the best hybrid predictive model (i.e., ANFIS-PSO) for both investigated scenarios and over both training and testing phases. On the one hand and over the training phase (Figure 6(a)), the PP-ANFIS-PSO attained $R^{2} \approx 0.934$ while NP-ANFIS-PSO attained $R^{2} \approx 0.904$. On the other hand, testing phase demonstrated PP-ANFIS-PSO attained $R^{2} \approx 0.865$ while NP-ANFIS-PSO attained $R^{2} \approx 0.741$. This is normal learning process as usually testing phase performs slightly worse than the training phase. This is might be due to the absence of the valuable information not comprehended perfectly.

Taylor diagrams were computed for the applied ANFIS, ANFIS-PSO, ANFIS-ACO, ANFIS-DE, and ANFIS-GA predictive models for both modeling phases (training and testing) and for both studied scenarios (see Figures 7 and 8), respectively. Taylor diagram is a summary of various statistical metrics including correlation, standard deviation, and root mean square. In accordance with the coordination of the predictive models from the benchmark (observed settlement records), the models are evaluated. In this way,
Taylor map delivers an excellent graphical representation of the models' accuracy. Figures 8(a) and 8(b) (preprocessed dataset scenario) indicate the hybrid ANFIS-PSO coordinated in the nearest position to the observed settlement measurements with correlation value over 0.95 for training phase and 0.92 for the testing phase, whereas ANFIS-ACO and ANFIS-DE displayed the largest distance from the observed benchmark record which signifies the worst prediction efficiency.

Among all the investigated hybrid intelligence models, the capacity of the ANFIS-PSO was demonstrated the superior potential over the other models. This is clearly an indication to the performance of the Particle Swarm Optimization algorithm for tuning the internal parameters of the ANFIS model and particularly for simulating the investigated geotechnical problem "i.e., shallow foundation settlement." It is worth to highlight that the ability of the PSO algorithm was approved for optimizing ANFIS model over multiple engineering applications such as channel sediment transport, basin bank shape optimization, compressive strength of intact roach, friction capacity ration of driven piles, oil flocculated asphaltene weight percentage, and several others [73-77].

Based on the attained modeling results, it is even better to highlight some valid critical observations to be established in future research. Settlement analysis is influenced by a certain level of uncertainty related to the variables influencing settlement behavior. Most of the existing methodologies conducted for settlement prediction on cohesionless soils do not consider the uncertainty component in the simulation. Hence, incorporating Monte Carlo model with the proposed hybrid ANFIS-PSO model can provide practical design tools for geotechnical engineering field where the inspection of the uncertainties associated with the 
variables affecting the settlement prediction is investigated. This is a very useful probabilistic approach in the sense that it can overcome the problems of the deterministic techniques and provide some guidance to the geotechnical engineers about the level of risk (i.e., degree of uncertainty) associated with the predicted settlement. Exploring other nature-inspired algorithms for optimizing ANFIS model can be further studied for better prediction accuracy [78-80].

\section{Conclusion and Remarks}

This research was emphasized on the implementation of newly developed hybrid intelligence model based on the integration of ANFIS model with various bioinspired optimization algorithms (e.g., PSO, ACO, DE, and GA). The main enthusiasm of the current investigation is to attain an accurate intelligent predictive model for shallow foundation settlement. The developed predictive models were inspected on large field measurements gathered from the open sources' literature. Two different modeling scenarios based on data processing were performed. Among the four hybrid models, ANFIS-PSO demonstrated an accurate prediction result with highest correlation value $R^{2} \approx 0.865$ and minimum absolute error measures $(\mathrm{RMSE}=9.02 \mathrm{~mm}$ and $\mathrm{MAE}=6.5 \mathrm{~mm}$ ) for the testing phase and within preprocessing data scenario. The proposition of the hybrid intelligent model evidenced an excellent alternative for the empirical formulation. In addition, the modeling scenarios proved the necessity to examine the potential of the raw data applicability for establishing predictive model. It is clearly verified that eliminating some irrelevant dataset has boosted the prediction accuracy remarkably.

\section{Data Availability}

The data used to support the findings of this study are available from the corresponding author upon request.

\section{Conflicts of Interest}

The authors have no conflicts of interest to publish this research.

\section{References}

[1] B. M. Das, Principles of Foundation Engineering, Cengage Learning, Boston, MA, USA, 9th edition, 2016.

[2] M. Maugeri, F. Castelli, M. R. Massimino, and G. Verona, "Observed and computed settlements of two shallow foundations on sand," Journal of Geotechnical and Geoenvironmental Engineering, vol. 124, no. 7, p. 595, 1998.

[3] D. P. Coduto, Foundation Design Principles and Practices, Prentice-Hall, Upper Saddle River, NJ, USA, 1994.

[4] A. R. Jumikis, "Introductory soil mechanics and foundations," Soil Science, vol. 112, no. 2, pp. 142-143, 1971.

[5] B. Das and N. Sivakugan, "Settlements of shallow foundations on granular soil-an overview," International Journal of Geotechnical Engineering, vol. 1, no. 1, 2007.

[6] Z. Zhang, F.-R. Rao, and G.-B. Ye, "Design method for calculating settlement of stiffened deep mixed column- supported embankment over soft clay," Acta Geotechnica, pp. 1-20, 2019.

[7] P. W. Mayne and H. G. Poulos, "Approximate displacement influence factors for elastic shallow foundations," Journal of Geo-Technical and Geoenvironmental Engineering, vol. 37, no. 12, pp. 3229-3235, 1999.

[8] G. A. Leonards and J. D. Frost, "Settlement of shallow foundations on granular soils," Journal of Geotechnical Engineering, vol. 114, no. 7, p. 791, 1988.

[9] F. C. Bungenstab and K. V. Bicalho, "Settlement predictions of footings on sands using probabilistic analysis," Journal of Rock Mechanics and Geotechnical Engineering, vol. 8, no. 2, pp. 198-203, 2016.

[10] B. Tarawneh, T. Masada, and S. Sargand, "Estimated and measured settlements of shallow foundation supporting bridge substructure," Jordan Journal of Civil Engineering, vol. 7, no. 2, 2013

[11] H.-C. Tsai, Y.-Y. Tyan, Y.-W. Wu, and Y.-H. Lin, "Determining ultimate bearing capacity of shallow foundations using a genetic programming system," Neural Computing and Applications, vol. 23, no. 7-8, pp. 2073-2084, 2013.

[12] B. Lehane and E. Cosgrove, "Applying triaxial compression stiffness data to settlement prediction of shallow foundations on cohesionless soil," Proceedings of the Institution of Civil Engineers-Geotechnical Engineering, vol. 143, no. 4, pp. 191200, 2000.

[13] J. B. Anderson, F. C. Townsend, L. Rahelison, M. Asce, F. C. Townsend, and L. Rahelison, "Load testing and settlement prediction of shallow foundation," Journal of Geotechnical and Geoenvironmental Engineering, vol. 133, no. 12, p. 1494, 2007.

[14] M. Y. Fattah, K. T. Shlash, and N. M. Salim, "Prediction of settlement trough induced by tunneling in cohesive ground," Acta Geotechnica, vol. 8, no. 2, pp. 167-179, 2013.

[15] ASTM-D1586, Standard Test Method for Standard Penetration Test (SPT) and Split-Barrel Sampling of Soils, ASTM International, West Conshohocken, PA, USA, 2008.

[16] P. K. Robertson and K. L. Cabal, Guide to Cone Penetration Testing for Geotechnical Engineering, Gregg Drilling \& Testing, Inc., Signal Hill, CA, USA, 2014.

[17] P. Mayne, "In-situ test calibrations for evaluating soil parameters," in Characterisation and Engineering Properties of Natural Soils, Taylor \& Francis, Abingdon, UK, 2006.

[18] N. C. Consoli, F. Schnaid, and J. Milititsy, "Interpretation of plate load tests on residual soil state," Journal of Geotechnical and Geoenvironmental Engineering, vol. 124, no. 9, p. 857, 1998.

[19] A. A. Jebur, W. Atherton, and R. M. Al Khaddar, "Feasibility of an evolutionary artificial intelligence (AI) scheme for modelling of load settlement response of concrete piles embedded in cohesionless soil," Ships and Offshore Structures, vol. 13, no. 7, pp. 705-718, 2018.

[20] M. A. Shahin, M. B. Jaksa, and H. R. Maier, "Artificial neural network applications in geotechnical engineering," Australian Geomechanics, vol. 36, pp. 49-62, 2001.

[21] H. Naderpour, K. Nagai, M. Haji, and M. Mirrashid, "Adaptive neuro-fuzzy inference modelling and sensitivity analysis for capacity estimation of fiber reinforced polymerstrengthened circular reinforced concrete columns," Expert Systems, vol. 36, no. 4, 2019.

[22] H. Naderpour, M. Mirrashid, and K. Nagai, "An innovative approach for bond strength modeling in FRP strip-to-concrete joints using adaptive neuro-fuzzy inference system," Engineering with Computers, pp. 1-18, 2019. 
[23] Z. M. Yaseen, H. A. Afan, and M.-T. Tran, "Beam-column joint shear prediction using hybridized deep learning neural network with genetic algorithm," IOP Conference Series: Earth and Environmental Science, vol. 143, p. 012025, 2018.

[24] A. A. Al-Musawi, A. A. H. Alwanas, S. Q. Salih, Z. H. Ali, M. T. Tran, and Z. M. Yaseen, "Shear strength of SFRCB without stirrups simulation: implementation of hybrid artificial intelligence model," Engineering with Computers, vol. 36, no. 1, pp. 1-11, 2018.

[25] A. A. H. Alwanas, A. A. Al-Musawi, S. Q. Salih, H. Tao, M. Ali, and Z. M. Yaseen, "Load-carrying capacity and mode failure simulation of beam-column joint connection: application of self-tuning machine learning model," Engineering Structures, vol. 194, pp. 220-229, 2019.

[26] A. Ashrafian, F. Shokri, M. J. Taheri Amiri, Z. M. Yaseen, and M. Rezaie-Balf, "Compressive strength of foamed cellular lightweight concrete simulation: new development of hybrid artificial intelligence model," Construction and Building Materials, vol. 230, p. 117048, 2020.

[27] A. Sharafati, M. Haghbin, D. Motta, and Z. M. Yaseen, "The application of soft computing models and empirical formulations for hydraulic structure scouring depth simulation: a comprehensive review, assessment and possible future research direction," Archives of Computational Methods in Engineering, pp. 1-25, 2019.

[28] C. I. Teh, K. S. Wong, A. T. C. Goh, and S. Jaritngam, "Prediction of pile capacity using neural networks," Journal of Computing in Civil Engineering, vol. 11, no. 2, pp. 129-138, 1997.

[29] J. Shi, J. A. R. Ortigao, and J. Bai, "Modular neural networks for predicting settlements during tunneling," Journal of Geotechnical and Geoenvironmental Engineering, vol. 124, no. 5, pp. 389-395, 1998.

[30] N. Sivakugan, J. Eckersley, and H. Li, "Settlement predictions using neural networks," Australian Civil Engineering Transactions, vol. 40, p. 49, 1998.

[31] R.-P. Chen, P. Zhang, X. Kang, Z.-Q. Zhong, Y. Liu, and H.-N. Wu, "Prediction of maximum surface settlement caused by earth pressure balance (EPB) shield tunneling with ANN methods," Soils and Foundations, vol. 59, no. 2, pp. 284-295, 2019.

[32] H. Moayedi and D. Jahed Armaghani, "Optimizing an ANN model with ICA for estimating bearing capacity of driven pile in cohesionless soil," Engineering with Computers, vol. 34, no. 2, pp. 347-356, 2018.

[33] S. Soleimani, P. Jiao, S. Rajaei, and R. Forsati, "A new approach for prediction of collapse settlement of sandy gravel soils," Engineering with Computers, vol. 34, no. 1, pp. 15-24, 2018.

[34] D. J. Armaghani, R. S. Faradonbeh, H. Rezaei, A. S. A. Rashid, and H. B. Amnieh, "Settlement prediction of the rocksocketed piles through a new technique based on gene expression programming," Neural Computing and Applications, vol. 29, no. 11, pp. 1115-1125, 2018.

[35] P. Samui, "Support vector machine applied to settlement of shallow foundations on cohesionless soils," Computers and Geotechnics, vol. 35, no. 3, pp. 419-427, 2008.

[36] P. Samui and T. G. Sitharam, "Least-square support vector machine applied to settlement of shallow foundations on cohesionless soils," International Journal for Numerical and Analytical Methods in Geomechanics, vol. 32, no. 17, pp. 2033-2043, 2008.

[37] J. Luo, C. Wu, X. Liu, D. Mi, F. Zeng, and Y. Zeng, "Prediction of soft soil foundation settlement in Guangxi granite area based on fuzzy neural network model," IOP Conference Series: Earth and Environmental Science, vol. 108, p. 032034, 2018.

[38] M. A. Shahin, H. R. Maier, and M. B. Jaksa, "Settlement prediction of shallow foundations on granular soils using B-spline neurofuzzy models," Computers and Geotechnics, vol. 30, no. 8, pp. 637-647, 2003.

[39] A. F. Cabalar, A. Cevik, and C. Gokceoglu, "Some applications of adaptive neuro-fuzzy inference system (ANFIS) in geotechnical engineering," Computers and Geotechnics, vol. 40, pp. 14-33, 2012.

[40] A. K. Kar, "Bio inspired computing-a review of algorithms and scope of applications," Expert Systems with Applications, vol. 59, pp. 20-32, 2016.

[41] Z. M. Yaseen, M. T. Tran, S. Kim, T. Bakhshpoori, and R. C. Deo, "Shear strength prediction of steel fiber reinforced concrete beam using hybrid intelligence models: a new approach," Engineering Structures, vol. 177, pp. 244-255, 2018.

[42] B. T. Pham, M. D. Nguyen, K.-T. T. Bui, I. Prakash, K. Chapi, and D. T. Bui, "A novel artificial intelligence approach based on multi-layer perceptron neural network and biogeographybased optimization for predicting coefficient of consolidation of soil," Catena, vol. 173, pp. 302-311, 2019.

[43] H. Ma, S. Shen, M. Yu, Z. Yang, M. Fei, and H. Zhou, "Multipopulation techniques in nature inspired optimization algorithms: a comprehensive survey," Swarm and Evolutionary Computation, vol. 44, pp. 365-387, 2019.

[44] S. Q. Salih and A. A. Alsewari, "A new algorithm for normal and large-scale optimization problems: nomadic people optimizer," Neural Computing and Applications, pp. 1-28, 2019.

[45] J.-S. R. Jang, "ANFIS: adaptive-network-based fuzzy inference system," IEEE Transactions on Systems, Man, and Cybernetics, vol. 23, no. 3, pp. 665-685, 1993.

[46] Z. M. Yaseen, M. M. Ramal, L. Diop, O. Jaafar, V. Demir, and O. Kisi, "Hybrid adaptive neuro-fuzzy models for water quality index estimation," Water Resources Management, vol. 32, no. 7, pp. 2227-2245, 2018.

[47] E. Momeni, D. J. Armaghani, S. A. Fatemi, and R. Nazir, "Prediction of bearing capacity of thin-walled foundation: a simulation approach," Engineering with Computers, vol. 34, no. 2, pp. 319-327, 2018.

[48] H. Naderpour and S. A. Alavi, "A proposed model to estimate shear contribution of FRP in strengthened RC beams in terms of adaptive neuro-fuzzy inference system," Composite Structures, vol. 170, pp. 215-227, 2017.

[49] H. Naderpour, A. Kheyroddin, and G. G. Amiri, "Prediction of FRP-confined compressive strength of concrete using artificial neural networks," Composite Structures, vol. 92, no. 12, pp. 2817-2829, 2010.

[50] T. Takagi and M. Sugeno, "Fuzzy identification of systems and its applications to modeling and control," IEEE Transactions on Systems, Man and Cybernetics, vol. SMC-15, no. 1, 1985.

[51] R. Fullér, Neural Fuzzy Systems, Åbo Akademi University, Turku, Finland, 1995.

[52] R. Eberhart and J. Kennedy, "A new optimizer using particle swarm theory," in Proceedings of the MHS'95 Proceedings of the Sixth International Symposium on Micro Machine and Human Science, pp. 39-43, Nagoya, Japan, October 1995.

[53] Y. Shi and R. C. Eberhart, "Empirical study of particle swarm optimization," in CEC 99: in Proceedings of the 1999 Congress on Evolutionary computation, vol. 3, pp. 1945-1950, Washington, DC, USA, July 1999.

[54] B. Chopard and M. Tomassini, "Particle swarm optimization," in Natural Computing Series, pp. 97-102, Springer, Berlin, Germany, 2018. 
[55] M. Dorigo, V. Maniezzo, and A. Colorni, "The ant systems: optimization by a colony of cooperative agents," IEEE Transactions on Man, Machine and Cybernetics-Part B, vol. $26,1996$.

[56] M. Dorigo and G. Di Caro, "Ant colony optimization: a new meta-heuristic," in Proceedings of the 1999 Congress on Evolutionary Computation, Washington, DC, USA, July 1999.

[57] D. Merkle, M. Middendorf, and H. Schmeck, "Ant colony optimization for resource-constrained project scheduling," IEEE Transactions on Evolutionary Computation, vol. 6, no. 4, 2002.

[58] M. Randall and A. Lewis, "A parallel implementation of ant colony optimization," Journal of Parallel and Distributed Computing, vol. 62, no. 9, pp. 1421-1432, 2002.

[59] R. Storn and K. Price, "Differential evolution-a simple and efficient heuristic for global optimization over continuous spaces," Journal of Global Optimization, vol. 11, 1997.

[60] A. K. Qin, V. L. Huang, and P. N. Suganthan, "Differential evolution algorithm with strategy adaptation for global numerical optimization," IEEE Transactions on Evolutionary Computation, vol. 13, no. 2, pp. 398-417, 2009.

[61] H. Iba and C. C. Aranha, "Introduction to genetic algorithms," in Adaptation, Learning, and Optimization, Berlin, Germany, 2012.

[62] J. Holland, "Adaptation in natural and artificial systems," University of Michigan Press, Ann Arbor, MI, USA, 1975.

[63] C. R. Houck, A Genetic Algorithm for Function Optimization: A Matlab Implementation, Technical Report 95-09, NCSU, Raleigh, NC, USA, 1995.

[64] T. Chai and R. R. Draxler, "Root mean square error (RMSE) or mean absolute error (MAE)?-arguments against avoiding RMSE in the literature," Geoscientific Model Development, vol. 7, no. 3, pp. 1247-1250, 2014.

[65] B. Keshtegar, M. Bagheri, and Z. M. Yaseen, "Shear strength of steel fiber-unconfined reinforced concrete beam simulation: application of novel intelligent model," Composite Structures, vol. 212, pp. 230-242, 2019.

[66] A. Sharafati, K. Khosravi, P. Khosravinia et al., "The potential of novel data mining models for global solar radiation prediction," International Journal of Environmental Science and Technology, vol. 16, no. 11, pp. 7147-7164, 2019.

[67] A. Sharafati, A. Tafarojnoruz, M. Shourian, and Z. M. Yaseen, "Simulation of the depth scouring downstream sluice gate: the validation of newly developed data-intelligent models," Journal of Hydro-Environment Research, 2019.

[68] A. Sharafati, R. Yasa, and H. M. Azamathulla, "Assessment of stochastic approaches in prediction of wave-induced pipeline scour depth," Journal of Pipeline Systems Engineering and Practice, vol. 9, no. 4, Article ID 04018024, 2018.

[69] M. A. Shahin, Use of Artificial Neural Networks for Predicting Settlement of Shallow Foundations on Cohesionless Soils, University of Adelaide, Department of Civil and Environmental Engineering, Adelaide, Australia, 2003.

[70] P. Malmir, M. Suleymani, and A. Bemani, "Application of ANFIS-PSO as a novel method to estimate effect of inhibitors on asphaltene precipitation," Petroleum Science and Technology, vol. 36, no. 8, pp. 597-603, 2018.

[71] M. H. Djavareshkian and A. Esmaeili, "Heuristic optimization of submerged hydrofoil using ANFIS-PSO," Ocean Engineering, vol. 92, pp. 55-63, 2014.

[72] D. P. Rini, S. M. Shamsuddin, and S. S. Yuhaniz, "Particle swarm optimization for ANFIS interpretability and accuracy," Soft Computing, vol. 20, no. 1, pp. 251-262, 2016.
[73] I. Ebtehaj, H. Bonakdari, and M. S. Es-haghi, "Design of a hybrid ANFIS-PSO model to estimate sediment transport in open channels," Iranian Journal of Science and Technology, Transactions of Civil Engineering, vol. 43, no. 4, pp. 851-857, 2019.

[74] A. Gholami, H. Bonakdari, I. Ebtehaj, M. Mohammadian, B. Gharabaghi, and S. R. Khodashenas, "Uncertainty analysis of intelligent model of hybrid genetic algorithm and particle swarm optimization with ANFIS to predict threshold bank profile shape based on digital laser approach sensing," Measurement, vol. 121, pp. 294-303, 2018.

[75] M. Rezaei and M. Asadizadeh, "Predicting unconfined compressive strength of intact rock using new hybrid intelligent models," Journal of Mining and Environment, vol. 10, 2019.

[76] H. Moayedi, M. Raftari, A. Sharifi, W. A. W. Jusoh, and A. S. A. Rashid, "Optimization of ANFIS with GA and PSO estimating a ratio in driven piles," Engineering with Computers, vol. 1-12, 2019.

[77] Z. Liu, D. Zhang, and W. Peng, "A novel ANFIS-PSO network for forecasting oil flocculated asphaltene weight percentage at wide range of operation conditions," Petroleum Science and Technology, vol. 36, no. 14, pp. 1044-1050, 2018.

[78] S. Q. Salih, "A new training method based on black hole algorithm for convolutional neural network," Journal of Southwest Jiaotong University, vol. 54, 2019.

[79] H. A. Abdulwahab, A. Noraziah, A. A. Alsewari, and S. Q. Salih, "An enhanced version of black hole algorithm via levy flight for optimization and data clustering problems," IEEE Access, vol. 7, pp. 142085-142096, 2019.

[80] W. Jing, Z. M. Yaseen, S. Shahid et al., "Implementation of evolutionary computing models for reference evapotranspiration modeling: short review, assessment and possible future research directions," Engineering Applications of Computational Fluid Mechanics, vol. 13, no. 1, pp. 811-823, 2019. 